\title{
RANCANGAN PERBAIKAN KURSI KERJA OPERATOR PADA BAGIAN PENJAHITAN AIRBAG DENGAN MENGGUNAKAN PENDEKATAN ANTROPOMETRI DAN SOFTWARE CATIA V5R19
}

\author{
Syarifuddin Nasution ${ }^{1}$, Nanih Suhartini ${ }^{2}$, Aditya Wahyu Nugroho ${ }^{3}$ \\ Jurusan Teknik Industri, Fakultas Teknologi Industri, Universitas Gunadarma, \\ Jl. Margonda Raya No. 100, Pondok Cina, Depok, 16424 \\ E-mail: synasution@staff.gunadarma.ac.id, nanihnoor@staff.gunadarma,ac,id, \\ laurensius.aditya@rocketmail.com
}

\begin{abstract}
ABSTRAK
Manusia dalam melakukan aktivitas kerja terkadang membutuhkan alat atau fasilitas yang dapat mempermudah dalam melakukan setiap kegiatan maupun pekerjaannya. Permasalahannya adalah beberapa operator sering mengeluhkan kondisi fisik pada saat melakukan pekerjaan disebabkan kursi kerja yang mereka gunakan tidak sesuai dengan dimensi tubuh operator, yang pada akhirnya memengaruhi produktivitas/kinerja operator. Tujuan penelitian ini adalah mengidentifikasi keluhan rasa sakit yang timbul pada bagian tubuh operator kerja bagian penjahitan, menentukan dimensi tubuh operator kerja penjahitan yang digunakan untuk usulan perbaikan kursi kerja, dan usulan perbaikan kursi kerja yang didapatkan dari hasil pengamatan kursi kerja sebelumnya. Pendekatan antropometri, kuisioner nordic body map, dan Catia V5R19 digunakan untuk perbaikan kursi kerja operator penjahitan tersebut. Terdapat beberapa pekerja mengeluh adanya rasa sakit pada bagian leher, lengan atas, bagian tangan, serta bagian kaki kanan yang berkaitan dengan sendi terasa nyeri. Perbaikan kursi kerja berdasarkan data antropometri adalah dimensi tinggi popliteal untuk tinggi kaki kursi kerja adalah $45 \mathrm{~cm}$, dimensi pantat popliteal untuk panjang alas kursi kerja adalah $52 \mathrm{~cm}$, dimensi lebar pinggul untuk lebar alas kursi kerja adalah $34 \mathrm{~cm}$, dimensi tinggi bahu posisi duduk untuk tinggi sandaran kursi kerja adalah $60 \mathrm{~cm}$, dimensi lebar bahu untuk lebar sandaran kursi kerja adalah $48 \mathrm{~cm}$, dimensi tinggi siku duduk untuk tinggi penyangga tangan adalah $24 \mathrm{~cm}$. Usulan perbaikan kursi kerja berdasarkan hasil pengamatan kursi kerja sebelumnya adalah adanya sandaran punggung, bantalan leher, penyangga tangan, serta pemakaian bahan tambahan seperti busa supaya lebih lunak yang itu semua dibuat untuk mengurangi resiko keluhan-keluhan fisik pada operator pada saat melakukan pekerjaan penjahitan airbag.
\end{abstract}

Kata kunci: Kursi kerja, nordic body map, antropometri, Catia V5R19

\begin{abstract}
Humans in carrying out work activities sometimes need tools or facilities that can make it easier to do every activity or work. The problem is that some operators often complain of physical conditions when doing work because the work chairs they use are not by the operator's body dimensions, which in turn affects the productivity/performance of the operator. The purpose of this study was to identify pain complaints that arise on the body part of the sewing work operator, determine the body dimensions of the sewing work operator that is used for anthropometric data proposed an improvement of work chairs, and the proposed improvement of work chairs obtained from observations of previous work chairs. An anthropometric approach and a Nordic body map questionnaire and Catia V5R19 were used to improve the work chair of the sewing operator. Several workers were complaining of pain in the neck, upper arm, part of the hand, and the right leg that was related to the joint felt pain. Work chair improvements based on anthropometric data are popliteal height dimensions for work chair leg height is $45 \mathrm{~cm}$, the dimensions of the popliteal buttocks for the length of the work chair base are $52 \mathrm{~cm}$, the dimensions of the hip width for the width of the work chair base is $34 \mathrm{~cm}$, dimension of the height of the shoulder sitting position for the height of the back of the work chair is $60 \mathrm{~cm}$, dimension of shoulder-width for seat back width is $48 \mathrm{~cm}$, dimension of elbow height for hand support height is $24 \mathrm{~cm}$. The proposed repair of work chairs based on the results of the design is the presence of backrests, neck pads, hand supports, and the use of additional materials such as foam to make it softer, all of which are made to reduce the risk of physical complaints at the operator when doing airbag sewing work.
\end{abstract}

Key words: work chair, nordic body map, anthropometry, Catia V5R19

\section{Pendahuluan}


Manusia dalam melakukan aktivitas kerja terkadang membutuhkan alat atau fasilitas yang dapat mempermudah dalam melakukan setiap kegiatan maupun pekerjaannya. Alat dan fasilitas yang digunakan oleh manusia terkadang tidak nyaman untuk digunakan karena tidak sesuai dengan karakteristik tubuh penggunanya, seperti kursi yang terlalu pendek atau terlalu tinggi. Hal tersebut dapat mengakibatkan berkurangnya konsentrasi yang pada akhirnya menyebabkan produktivitas dari penggunanya menjadi menurun. Oleh karena itu, dibutuhkan suatu rancangan produk yang sesuai dengan dimensi tubuh manusia, sehingga manusia dapat merasa nyaman pada saat menggunakan alat atau fasilitas dalam membantu kegiatannya $[1,2,3]$. Dalam penelitian ini akan dikaji mengenai rancangan perbaikan kursi kerja operator bagian penjahitan airbag pada PT. XYZ.

Produk cargo airbag pada PT. XYZ adalah suatu kantong udara yang gunanya untuk melindungi barang-barang yang sifatnya besar seperti televisi, kulkas supaya tidak terbentur maupun goyah pada saat barang tersebut dikirim dengan menggunakan kapal laut. Proses produksi cargo airbag ini dalam pengerjaanya meliputi proses seperti pemotongan, penjahitan, pengepressan, dan juga proses penyortiran. Pengamatan ditujukan lebih kepada kursi kerja operator pengerjaan penjahitan cargo airbag di mana pada proses ini merupakan proses yang memerlukan waktu paling lama dibanding proses lainnya. Pada pengamatan pendahuluan, terdapat beberapa operator yang sering mengeluhkan kondisi fisik pada saat melakukan pekerjaan tersebut karena kursi kerja yang mereka gunakan tidak sesuai dengan dimensi tubuh operator tersebut. Kondisi tersebut dapat memengaruhi produktivitas/kinerja operator di dalam pekerjaannya.

Berdasarkan penjelasan di atas, untuk perbaikan kursi kerja operator menggunakan pendekatan antropometri yang berupa kumpulan data numerik berhubungan dengan dimensi tubuh operator serta menggunakan kuesioner nordic body map untuk mengetahui keluhan fisik atau bagian mana yang nantinya akan dijadikan penerapan perbaikan dari kursi kerja operator penjahitan tersebut. Selanjutnya, usulan perbaikan kursi kerja dirancang dengan menggunakan perangkat lunak Catia V5R19 karena fitur di dalam perangkat lunak tersebut lebih lengkap dan fleksibel [4]. Penggunakan kursi yang ergonomis harus sesuai dengan dimensi tubuh operator tersebut sehingga produk yang dirancang dapat memberikan rasa nyaman yang nantinya dapat meningkatkan konsentrasi pengguna dan mendorong pengguna menjadi fokus dalam bekerja.

Tujuan penelitian ini adalah mengidentifikasi keluhan rasa sakit yang timbul pada bagian tubuh operator kerja penjahitan, menentukan dimensi tubuh operator kerja penjahitan yang digunakan untuk data antropometri usulan perbaikan kursi kerja, dan usulan perbaikan kursi kerja yang didapatkan dari hasil pengamatan kursi kerja sebelumnya.

\section{Metodologi Penelitian}

\section{Objek Penelitian}

Penelitian diambil di PT. XYZ berupa produk airbag. PT. XYZ berlokasi di Kawasan Industri Jababeka Cikarang. Objek yang diamati dalam penelitian ini adalah pada proses penjahitan airbag terutama kursi yang dipakai dalam melakukan kegiatan pekerjaan sehari-hari (selama 7 jam). Objek ini diambil karena pada proses pembuatan airbag, proses penjahitan memerlukan waktu pekerjaan yang paling lama diantara proses lainnya.

\section{Studi Pendahuluan}

Studi pendahuluan ini harus didukung atau dipandu dengan studi pustaka, studi pustaka adalah cara yang dipakai untuk menghimpun data-data atau sumber-sumber yang berhubungan dengan topik yang diangkat dalam suatu penelitian.

\section{Pengumpulan Data}

Tahapan selanjutnya adalah pengumpulan data. Dalam usulan perancangan perbaikan kursi kerja operator data yang dibutuhkan adalah keluhan-keluhan fisik operator pada saat menggunakan kursi kerja terdahulu dengan cara kuesioner nordic body map yang dilakukan secara langsung mewawancari operator tersebut. Pengambilan data dilakukan dengan teknik sampling jenuh yaitu teknik penentuan sampel bila anggota populasi digunakan sebagai sampel dan antropometri atau dimensi tubuh dari operator tersebut. Jumlah sampel sebanyak 4 orang.

\section{Pengolahan Data}

Data yang sudah diambil kembali di cek, apabila masih terdapat data yg tidak lengkap atau tidak terpenuhi maka harus dilakukan pengambilan data ulang, namun apabila data sudah lengkap maka data tersebut siap untuk dilakukan diolah. Pengolahan data dalam penelitian ini adalah data kuesioner nordic body map dihitung agar menghasilkan persentase keluhan fisik kerja operator yang dibuat juga dalam bentuk diagram. Dari hasil 
keluhan tersebut dapat disimpulkan bagian mana kursi kerja yang diperlukan perbaikan. Selanjutnya data yang diolah adalah data antropometri atau dimensi tubuh operator yang digunakan untuk usulan perbaikan kursi kerja. Data antropometri yang diukur diantaranya dimensi tinggi popliteal untuk tinggi kaki kursi kerja, dimensi pantat popliteal untuk panjang alas kursi kerja, dimensi lebar pinggul untuk lebar alas kursi kerja, dimensi tinggi bahu posisi duduk untuk tinggi sandaran kursi kerja, dimensi lebar bahu untuk lebar sandaran kursi kerja, dan dimensi tinggi siku duduk untuk tinggi penyangga tangan.

\section{Analisis Hasil}

Tahapan selanjutnya adalah melakukan analisis hasil dari perancangan perbaikan kursi kerja operator penjahitan produk airbag. Analisis hasil ukuran perancangan produk kursi kerja menggunakan persentil rata-rata yaitu $50 \%$. Analisis perbandingan antara kursi terdahulu dan kursi perbaikan.

\section{Alat Penelitian}

Alat-alat yang digunakan untuk menunjang kegiatan penelitian adalah sebagai berikut.

1) Alat tulis untuk mencatat data yang diperlukan.

2) Meteran besi dan penggaris untuk mengukur dimensi tubuh operator.

3) Lembar data nordic body map dan lembar data antropometri.

4) Laptop atau komputer untuk mengolah data dan analisis.

5) Kamera untuk alat dokumentasi.

\section{Software yang Digunakan}

Software yang digunakan dalam pengolahan software adalah SPSS, sedangkan untuk pembuatan gambar adalah Catia V5R19

\section{Hasil dan Pembahasan}

\section{Identifikasi Keluhan Fisik Operator}

Identifikasi ini didapatkan dengan cara pengolahan data nordic body map dari data kuesioner yang telah diberikan kepada responden. Pengisian data nordic body map diambil dengan cara menanyakan langsung secara satu persatu kepada operator penjahitan airbag. Data kuesioner nordic body map bertujuan untuk mengetahui bagian-bagian otot yang mengalami keluhan saat bekerja yang dirasakan oleh pekerja. Terdapat 4 data kuesioner nordic body map sesuai dengan jumlah pekerja penjahitan cargo airbag dan dalam satu data kuesioner nordic body map terdapat 27 data mengenai keluhan fisik.

Berdasarkan Tabel 1, dapat dilihat besarnya persentase dari setiap keluhan fisik yang dirasakan pada keempat operator penjahitan airbag. Dibuat diagaram keluhan fisik agar lebih jelas dalam pengamatan. Persentase apabila terdapat keluhan berjumlah satu nilainya sebesar $25 \%$, dan jika terdapat keluhan berjumlah empat nilainya sebesar $100 \%$. Hasil tersebut dapat dibuat diagram keluhan fisik agar lebih jelas dalam pengamatannya. Grafik persentase keluhan pekerja ditunjukkan pada Gambar 1.

Berdasarkan Gambar 1, diketahui bahwa keluhan fisik berupa rasa sakit dominan dirasakan di punggung, pinggang, dipinggul, dan juga pantat. Terdapat juga keluhan fisik pada bagian leher, lengan atas atas, dan bagian tangan. Faktor ini dikarenakan kurang nyamannya alat bantu kerja yaitu berupa kursi yang dipakai dalam tiap harinya saat melakukan kegiatan pekerjaan. Untuk merancang kursi yang ergonomis berdasarkan keluhan fisik operator dapat dilakukan pengamatan dalam pengukuran dimensi tubuh atau antropometri. Tabel 2 menunjukkan dimensi tubuh yang diukur untuk merancang perbaikan kursi kerja operator.

\section{Perhitungan Antropometri}

Perhitungan antropometri atau dimensi tubuh yang digunakan untuk merancang sebuah kursi kerja meliputi keseragaman data, perhitungan antropometri secara manual, perhitungan antropometri menggunakan software, dan rancangan ukuran antropometri. Terdapat 6 dimensi tubuh untuk membuat atau merancang sebuah kursi kerja. Tabel 2 menunjukkan dimensi tubuh yang digunakan dalam perancangan.

Terdapat enam dimensi tubuh dari ke empat operator penjahitan produk cargo airbag. Keenam dimensi tersebut antara lain tinggi popliteal, pantat popliteal, lebar pinggul, tinggi bahu dalam posisi duduk, lebar bahu, dan tinggi siku duduk. 
Tabel 1. Rangkuman persentase keluhan pekerja

\begin{tabular}{|c|c|c|c|c|c|c|c|c|c|}
\hline \multirow{3}{*}{ No } & \multirow{3}{*}{ Jenis Keluhan } & \multicolumn{8}{|c|}{ Tingkat Keluhan } \\
\hline & & \multicolumn{2}{|c|}{ Tidak Sakit } & \multicolumn{2}{|c|}{ Agak Sakit } & \multicolumn{2}{|c|}{ Sakit } & \multicolumn{2}{|c|}{ Sangat Sakit } \\
\hline & & Jumlah & $\%$ & Jumlah & $\%$ & Jumlah & $\%$ & Jumlah & $\%$ \\
\hline 0 & Sakit/kaku di leher atas & 2 & 50 & 1 & 25 & 1 & 25 & 0 & 0 \\
\hline 1 & Sakit/kaku di leher bawah & 3 & 75 & 0 & 0 & 1 & 25 & 0 & 0 \\
\hline 2 & Sakit di bahu kiri & 4 & 100 & 0 & 0 & 0 & 0 & 0 & 0 \\
\hline 3 & Sakit di bahu kanan & 4 & 100 & 0 & 0 & 0 & 0 & 0 & 0 \\
\hline 4 & Sakit di lengan atas kiri & 4 & 100 & 0 & 0 & 0 & 0 & 0 & 0 \\
\hline 5 & Sakit di punggung & 0 & 0 & 0 & 0 & 3 & 75 & 1 & 25 \\
\hline 6 & Sakit di lengan atas kanan & 3 & 75 & 1 & 25 & 0 & 0 & 0 & 0 \\
\hline 7 & Sakit di pinggang & 0 & 0 & 0 & 0 & 4 & 100 & 0 & 0 \\
\hline 8 & Sakit di pinggul & 0 & 0 & 3 & 75 & 1 & 25 & 0 & 0 \\
\hline 9 & Sakit di bagian pantat & 0 & 0 & 1 & 25 & 3 & 75 & 0 & 0 \\
\hline 10 & Sakit pada siku kiri & 4 & 100 & 0 & 0 & 0 & 0 & 0 & 0 \\
\hline 11 & Sakit pada siku kanan & 3 & 75 & 1 & 25 & 0 & 0 & 0 & 0 \\
\hline 12 & Sakit pada lengan bawah kiri & 4 & 100 & 0 & 0 & 0 & 0 & 0 & 0 \\
\hline 13 & Sakit pada lengan bawah kanan & 3 & 75 & 1 & 25 & 0 & 0 & 0 & 0 \\
\hline 14 & Sakit pada pergelangan tangan kiri & 3 & 75 & 1 & 25 & 0 & 0 & 0 & 0 \\
\hline 15 & Sakit pada pergelangan tangan kanan & 2 & 50 & 2 & 50 & 0 & 0 & 0 & 0 \\
\hline 16 & Sakit pada tangan kiri & 4 & 100 & 0 & 0 & 0 & 0 & 0 & 0 \\
\hline 17 & Sakit pada tangan kanan & 1 & 25 & 3 & 75 & 0 & 0 & 0 & 0 \\
\hline 18 & Sakit pada paha kiri & 4 & 100 & 0 & 0 & 0 & 0 & 0 & 0 \\
\hline 19 & Sakit pada paha kanan & 2 & 50 & 2 & 50 & 0 & 0 & 0 & 0 \\
\hline 20 & Sakit pada lutut kiri & 4 & 100 & 0 & 0 & 0 & 0 & 0 & 0 \\
\hline 21 & Sakit pada lutut kanan & 4 & 100 & 0 & 0 & 0 & 0 & 0 & 0 \\
\hline 22 & Sakit pada betis kiri & 4 & 100 & 0 & 0 & 0 & 0 & 0 & 0 \\
\hline 23 & Sakit pada betis kanan & 3 & 75 & 1 & 25 & 0 & 0 & 0 & 0 \\
\hline 24 & Sakit pada pergelangan kaki kiri & 4 & 100 & 0 & 0 & 0 & 0 & 0 & 0 \\
\hline 25 & Sakit pada pergelangan kaki kanan & 2 & 50 & 2 & 50 & 0 & 0 & 0 & 0 \\
\hline 26 & Saki pada kaki kiri & 4 & 100 & 0 & 0 & 0 & 0 & 0 & 0 \\
\hline 27 & Sakit pada kaki kanan & 4 & 100 & 0 & 0 & 0 & 0 & 0 & 0 \\
\hline
\end{tabular}

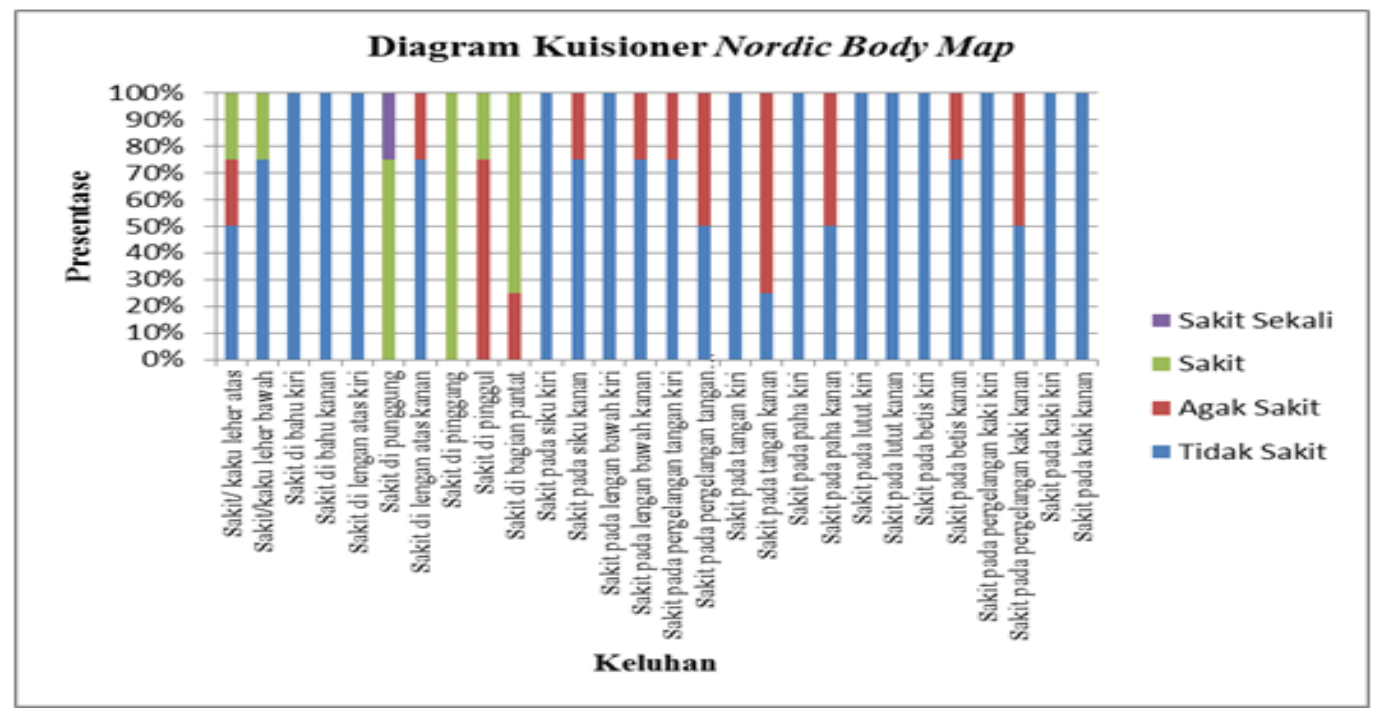

Gambar 1. Grafik persentase keluhan pekerja

\section{Perhitungan Manual Antropometri}

Perhitungan manual adalah menghitung besar dimensi-dimensi tubuh yang digunakan sesuai dengan perhitungan yang didapatkan sesuai dengan rumus-rumus yang ada. Perhitungan yang dilakukan adalah mencari nilai mean, standar deviasi, dan nilai persentil. 
Tabel 2. Lembar dimensi tubuh

\begin{tabular}{|c|c|c|c|c|c|c|}
\hline \multicolumn{7}{|c|}{ Lembar Pengamatan Pengukuran Data Antropometri Statis } \\
\hline \multirow{4}{*}{\multicolumn{2}{|c|}{$\begin{array}{l}\text { Keterangan } \\
\text { Shift } \\
\text { Jenis Kelamin } \\
\text { Suku Bangsa }\end{array}$}} & \multirow{4}{*}{$\begin{array}{l}\text { : Operator } \\
\text { : } 1 \\
\text { : Laki-laki } \\
\text { : Indonesia }\end{array}$} & njahitan Car & Airbag & & \\
\hline & & & & & & \\
\hline & & & & & & \\
\hline & & & & & & \\
\hline \multirow{2}{*}{ No. } & \multirow{2}{*}{ Data yang Diukur } & \multirow{2}{*}{ Simbol } & \multicolumn{4}{|c|}{ Hasil Pengukuran (cm) } \\
\hline & & & Kurniawan & Aang & Yusuf & Ade \\
\hline 1 & Tinggi popliteal & Tpo & 42 & 41 & 42 & 43 \\
\hline 2 & Pantat popliteal & $\mathrm{Pp}$ & 49 & 51 & 53 & 41 \\
\hline 3 & Lebar pinggul & Lpg & 34 & 30 & 30 & 31 \\
\hline 4 & $\begin{array}{l}\text { Tinggi bahu dalam } \\
\text { posisi duduk }\end{array}$ & Tbd & 56,5 & 56 & 56 & 55 \\
\hline 5 & Lebar bahu & $\mathrm{Lb}$ & 45 & 44 & 47 & 41 \\
\hline 6 & Tinggi siku duduk & Tsd & 18 & 21 & 20 & 21 \\
\hline
\end{tabular}

Perhitungan yang dilakukan adalah sebagai berikut.

1. Mean ukuran dalam pembuatan produk kursi kerja bisa diketahui dengan mencari nilai rata-rata hitung untuk data tunggal. Berikut merupakan contoh perhitungan nilai mean untuk dimensi tinggi popliteal [4].

$$
\begin{aligned}
& \bar{X}=\frac{42+41+42+43}{4} \\
& \bar{X}=42 \mathrm{~cm}
\end{aligned}
$$

2. Standar deviasi atau simpangan baku dari data yang diukur. Simpangan baku adalah akar dari tengah kuadrat simpangan dari nilai tengah atau akar simpangan rata-rata kuadrat. Berikut merupakan contoh perhitungan nilai standar deviasi untuk dimensi tinggi popliteal.

$$
\begin{aligned}
s & =\sqrt{\frac{(46-48)^{2}+(54-48)^{2}+(48-48)^{2}+(44-48)^{2}}{4-1}} \\
& =\frac{\sqrt{6}}{3} \\
& =0,82 \mathrm{~cm}
\end{aligned}
$$

3. Persentil $50 \%$ menunjukkan suatu nilai rata-rata dari ukuran populasi yang diukur dimensi tubuhnya. Berikut merupakan contoh perhitungan persentil 50\% untuk dimensi tinggi popliteal [2].

$$
\begin{aligned}
\text { Persentil } 50 \% & =\bar{X} \\
& =42 \mathrm{~cm}
\end{aligned}
$$

Adapun rangkuman dari perhitungan secara manual berdasarkan dimensi tubuh yang digunakan dalam usulan perbaikan kursi kerja ditunjukkan Pada Tabel 3. Tabel 3 berisi nilai rata-rata, standar deviasi, dan persentil. Dimensi tubuh yang digunakan dalam proses perancangan produk kursi kerja tersebut dilakukan keseragaman data. Uji keseragaman data dapat diperlihatkan apakah data tersebut masuk dalam kontrol atau tidak.

\section{Pengolahan Software Antropometri}

Pengolahan software adalah menghitung besar dimensi-dimensi tubuh dengan menggunakan aplikasi software SPSS.16.0. Pengolahan software tersebut meliputi perhitungan dari mean, standar deviasi, dan persentil 5\%, $50 \%$, dan 95\%. Hasil pengolahan data dimensi antropometri ditunjukkan pada Gambar 2.

Hasil output software pada Gambar 2 hanya meliputi data statistcs saja yaitu data dari keempat objek yang dimasukkan ke dalam software spss.16.0. Data dari keempat objek tersebut berhasil diolah semua tidak ada data yang gagal atau tidak diolah. Pengolahan software ini mengolah 6 data dimensi yang digunakan untuk merancang usulan kursi kerja.

\section{Rancangan Antropometri Produk Usulan Kursi Kerja}

Perancangan produk pada kursi kerja ini mempunyai enam dimensi tubuh untuk mewakili bagian-bagian dari kursi kerja tersebut. Dimensi yang dipakai adalah tinggi popliteal, pantat popliteal, lebar pinggul, tinggi sandaran punggung, lebar bahu, dan tinggi siku duduk. Perancangan kursi kerja ini menggunakan persentil ratarata yaitu seberar $50 \%$. 


\begin{tabular}{|c|c|c|c|c|c|c|c|}
\hline \multicolumn{8}{|c|}{ Statistics } \\
\hline & & $\begin{array}{l}\text { Tinggi } \\
\text { Popliteal }\end{array}$ & $\begin{array}{l}\text { Pantat } \\
\text { Popliteāa }\end{array}$ & $\begin{array}{l}\text { Lebar } \\
\text { Pingaū }\end{array}$ & $\begin{array}{c}\text { Tinggi_Bahu_ } \\
\text { Duduk }\end{array}$ & Lebar_Bahu & $\begin{array}{c}\text { Tinggi_Siku_ } \\
\text { Duduk }\end{array}$ \\
\hline \multirow[t]{2}{*}{$\bar{N}$} & Valid & 4 & 4 & 4 & 4 & 4 & 4 \\
\hline & Missing & 0 & 0 & 0 & 0 & 0 & 0 \\
\hline Mean & & 42.00 & 48.50 & 31.25 & 55.88 & 44.25 & 20.00 \\
\hline Std. Deviation & & .816 & 5.260 & 1.893 & .629 & 2.500 & 1.414 \\
\hline \multirow[t]{3}{*}{ Percentiles } & 5 & 41.00 & 41.00 & 30.00 & 55.00 & 41.00 & 18.00 \\
\hline & 50 & 42.00 & 50.00 & 30.50 & 56.00 & 44.50 & 20.50 \\
\hline & 95 & 43.00 & 53.00 & 34.00 & 56.50 & 47.00 & 21.00 \\
\hline
\end{tabular}

Gambar 2. Output software SPSS 16.0

Tabel 3. Data-data perhitungan secara manual

\begin{tabular}{lcccccc}
\hline \multicolumn{1}{c}{ Dimensi } & Total & Mean & $\begin{array}{c}\text { Standar } \\
\text { Deviasi }\end{array}$ & $\begin{array}{c}\text { Persentil } \\
\mathbf{5 \%}\end{array}$ & $\begin{array}{c}\text { Persentil } \\
\mathbf{5 0 \%}\end{array}$ & $\begin{array}{c}\text { Persentil } \\
\mathbf{9 5 \%}\end{array}$ \\
\hline Tinggi popliteal & 168 & 42 & 0,82 & 40,65 & 42 & 43,35 \\
Pantat popliteal & 194 & 48,5 & 5,26 & 39,85 & 48,5 & 57,15 \\
Lebar pinggul & 125 & 31,25 & 1,90 & 28,12 & 31,25 & 34,38 \\
Tinggi bahu dalam posisi duduk & 223,5 & 55,88 & 0,63 & 54,84 & 55,88 & 56,92 \\
Lebar bahu & 177 & 44,25 & 2,5 & 40,14 & 44,25 & 48,36 \\
Tinggi siku duduk & 80 & 20 & 1,41 & 17,68 & 20 & 22,32 \\
\hline
\end{tabular}

Tabel 5. Rangkuman dimensi perancangan perbaikan kursi kerja

\begin{tabular}{clc}
\hline No & \multicolumn{1}{c}{ Dimensi } & Ukuran $(\mathrm{Cm})$ \\
\hline 1 & Tinggi kaki kursi kerja & 45 \\
2 & Panjang alas kursi kerja & 52 \\
3 & Lebar alas kursi kerja & 34 \\
4 & Tinggi sandaran kursi kerja & 60 \\
5 & Lebar sandaran kursi kerja & 48 \\
6 & Tinggi penyangga tangan & 24 \\
\hline
\end{tabular}

\section{Usulan Desain Produk}

Perancangan usulan produk pada kursi kerja ini memiliki desain 3D menggunakan perangkat lunak Catia. Usulan desain produk dibandingkan dengan produk kursi kerja terdahulu. Dimensi tubuh yang diukur dan digunakan untuk merancang sebuah usulan kursi kerja dari produk sebelumnya dibuat dalam gambar 3D yang menampilkan suatu gambar seperti bentuk aslinya. Gambar 3 menunjukkan perbandingan desain produk.

Kursi kerja terdahulu memiliki ukuran dimensi sebesar panjang $29 \mathrm{~cm}$, lebar $30 \mathrm{~cm}$, dan tinggi $65 \mathrm{~cm}$. Usulan desain kursi kerja yang dibuat berdasarkan dimensi tubuh operator sebesar tinggi kaki kursi kerja $45 \mathrm{~cm}$, panjang alas kursi kerja $52 \mathrm{~cm}$, lebar alas kursi kerja $34 \mathrm{~cm}$, tinggi sandaran kursi kerja $60 \mathrm{~cm}$, lebar sandaran kursi kerja $48 \mathrm{~cm}$, dan tinggi penyangga tangan $24 \mathrm{~cm}$. Pada kursi kerja terdahulu bahan hanya berupa kayu seperti balok yang dirakit menjadi tempat duduk dan tanpa sandaran punggung. Pada kursi kerja usulan dibuat desain dengan menggunakan bahan kayu namun pada bagian alas tempat duduk, sandaran punggung, penyangga tangan diberi busa supaya operator tersebut dapat menyandarkan tubuhnya ketika sedang mengalami kelelahan. Perbedaan selanjutnya dari kursi tersebut dibuatkannya bantalan busa pada bagian leher atas maupun leher bawah untuk menyandarkan bagian leher ketika sedang mengalami kelelahan. Perbedaan yang lainnya adalah adanya penyangga tangan, pada kursi kerja terdahulu tidak ada penyangga tangan sedangkan pada usulan perbaikan kursi kerja ada dan juga terdapat penyangga tangan yang membentuk segitiga atau siku yang fungsinya untuk menahan tangan ketika sedang melakukan pekerjaan penjahitan. Penyangga tangan segitiga dibuat secara fleksibel apabila ingin digunakan dapat dikaitkan dengan kaitan besi namun apabila tidak ingin digunakan kaitan tersebut dapat dilepas sehingga penyangga tersebut dapat diturunkan menghadap vertikal.

Gambar 4 menunjukkan tampak visual dari pengguna yang disimulasikan terhadap manikin pada perangkat lunak Catia V5R19. Terlihat bahwa produk usulan kursi kerja yang telah dibuat berdasarkan antropometri atau dimensi tubuh operator pada manikin sangat cocok dan ideal. Tujuan dari visualisasi terhadap manikin yaitu menjelaskan secara rinci mengenai produk apakah ukuran yang ditetapkan telah sesuai dengan yang dihasilkan pada alat bantu Catia V5R19 dengan persentil 50\%. 


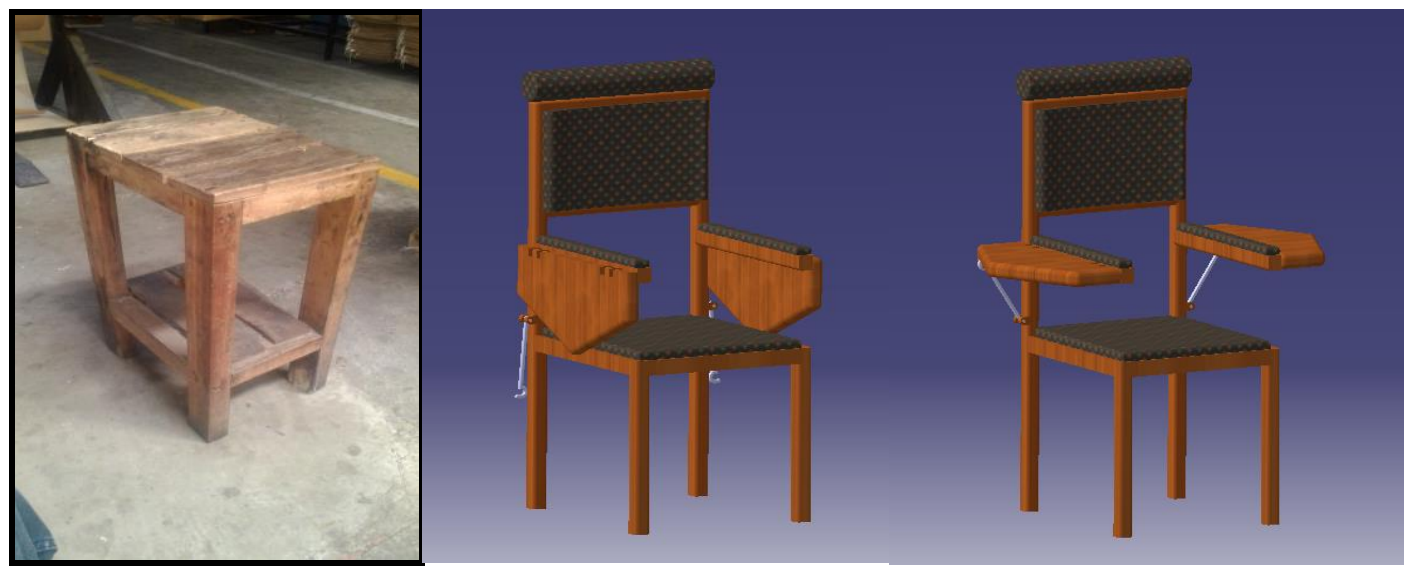

(a)

(b)

Gambar 3. Perbandingan produk (a) kursi kerja terdahulu dan (b) kursi kerja hasil perbaikan

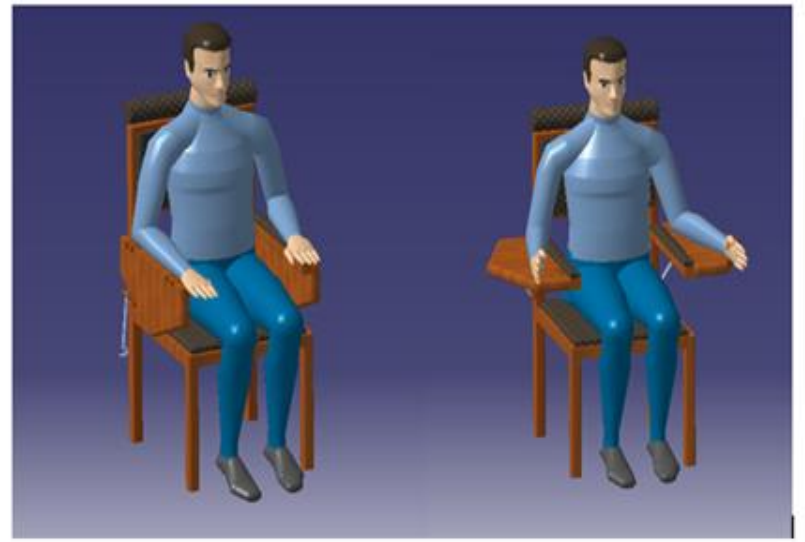

Gambar 4. Produk jadi beserta manikin

Pada kuesioner body nordic map didapatkan keluhan dominan yaitu rasa sakit pada bagian pinggul, punggung, dan pinggang karena kurang nyamannya kursi kerja yang dipakai saat melakukan pekerjaan, oleh karena itu peneliti membuat desain dengan merancang sandaran punggung berdasarkan dimensi tubuh operator penjahit airbag. Keluhan rasa sakit pada bagian leher juga dibuat perbaikan pada kursi tersebut berupa bantalan leher yang bahannya lunak seperti busa untuk menyandarkan leher. Keluhan lainnya yaitu pada daerah tangan sehingga peneliti membuat desain penyangga tangan dengan bentuk siku atau segitiga.

\section{Kesimpulan}

Berdasarkan hasil output dan hasil analisis, maka dapat disimpulkan beberapa hal sebagai berikut.

1. Identifikasi keluhan rasa sakit yang timbul pada bagian tubuh operator jahit pada saat melakukan pekerjaan penjahitan diantaranya adalah rasa sakit pada bagian leher (kekakuan dari pada otot-otot leher), lengan atas, bagian tangan, dan bagian kaki kanan yang berkaitan dengan sendi terasa nyeri. Terdapat juga keluhan rasa sakit dominan pada bagian punggung, pinggang, dan pinggul yang menyebabkan gejala utama nyeri atau perasaan lain yang tidak enak dan tidak nyaman di daerah punggung bagian bawah.

2. Dimensi tubuh operator mesin jahit yang digunakan untuk data antropometri usulan perbaikan kursi kerja berjumlah enam yaitu dimensi tinggi popliteal untuk tinggi kaki kursi kerja adalah $45 \mathrm{~cm}$, dimensi pantat popliteal untuk panjang alas kursi kerja adalah $52 \mathrm{~cm}$, dimensi lebar pinggul untuk lebar alas kursi kerja adalah $34 \mathrm{~cm}$, dimensi tinggi bahu posisi duduk untuk tinggi sandaran kursi kerja adalah $60 \mathrm{~cm}$, dimensi lebar bahu untuk lebar sandaran kursi kerja adalah $48 \mathrm{~cm}$, dan dimensi tinggi siku duduk untuk tinggi penyangga tangan adalah $24 \mathrm{~cm}$.

3. Usulan perbaikan kursi kerja berdasarkan hasil perancangan yang membedakan dari kursi kerja sebelumnya adalah dimensi kursi kerja perbaikan yang berbeda dengan kursi sebelumnya. Adanya sandaran punggung, bantalan leher, penyangga tangan, dan pemakaian bahan tambahan seperti busa supaya lebih lunak yang itu semua dibuat untuk mengurangi resiko keluhan-keluhan fisik pada operator pada saat melakukan pekerjaan penjahitan airbag. 


\section{Referensi}

[1] S. Wignjosoebroto, Ergonomi, studi gerak, dan waktu. Surabaya: Guna Widya, 2003.

[2] E. Nurmianto, Ergonomi konsep dasar dan aplikasi, edisi kedua. Surabaya: Guna Widya, 2004.

[3] I. Z. Sutalaksana, Teknik tata cara kerja. Bandung: Labolatorium Tata Cara Kerja \& Ergonomi, Departemen Teknik Industri ITB, 2006.

[4] M. D. Pinem, CATIA si jago desain tiga dimensi. Jakarta: Kawah Media, 2009.

[5] M. I. Hasan, Pokok-pokok materi statistik 1. Jakarta: PT Bumi Aksara, 2001. 